See Article page 1.

\section{Commentary: Do not close a door that opens a window!}

\author{
Ilaria Giambuzzi, MD, ${ }^{\text {a,b }}$ Giorgia Bonalumi, MD, ${ }^{\mathrm{a}}$ \\ Alessandro Parolari, $\mathrm{MD}, \mathrm{PhD},{ }^{\mathrm{c}}$ and \\ Michele Di Mauro, MD, PhD, MSc ${ }^{\mathrm{d}}$
}

Total arch replacement (TAR) and hemiarch/ascending aorta replacement (nTAR) are both considered the surgical standard of care for the treatment of acute type A aortic dissection (ATAAD) according to the location of the intimal tear into the aortic arch. ${ }^{1}$ It is still controversial whether an aggressive approach to ATAAD by performing a TAR can provide better results than a less aggressive surgery. ${ }^{2}$ However, it has been highlighted that the residual entry tear may carry the risk of causing a progressive aortic dilatation during follow-up, increasing the probability of aortic reoperation and late mortality. ${ }^{3}$ White and colleagues ${ }^{4}$ performed a literature review regarding the behavior of aortic true lumen and false lumen (FL) after surgery, the distal anastomotic new entry tear (DANE), and their influence on the prognosis and, therefore, strategies to improve it.

White and colleagues ${ }^{4}$ discuss the influence of the FL at the presentation of ATAAD and its implication on organ malperfusion, which still is among the most fearful complications. ${ }^{5}$ Indeed, even after surgery, a pressurized FL has a strong influence on survival (as low as $42 \%$ ) and aortic reinterventions, in whom an FL was patent in up to $96 \%$ of patients. Moreover, the authors supported the thesis that a DANE permits a continuous FL

\footnotetext{
From the ${ }^{\text {a Department }}$ of Cardiac Surgery, IRCCS Monzino Cardiology Center, Milan, Italy; ${ }^{\mathrm{b}}$ Dipartimento Scienze Cliniche e di Comunità, and ${ }^{\mathrm{c}}$ Unit of Cardiac Surgery and Translational Research, IRCCS Policlinico S. Donato, University of Milan, Milan, Italy; and ${ }^{\mathrm{d}}$ Cardio-Thoracic Surgery Unit, Heart and Vascular Centre, Maastricht University Medical Centre, Maastricht, the Netherlands. Disclosures: The authors reported no conflicts of interest.

The Journal policy requires editors and reviewers to disclose conflicts of interest and to decline handling or reviewing manuscripts for which they may have a conflict of interest. The editors and reviewers of this article have no conflicts of interest. Drs Giambuzzi and Bonalumi contributed equally to this article.

Received for publication June 14, 2021; revisions received June 14, 2021; accepted for publication June 18, 2021; available ahead of print June 24, 2021.

Address for reprints: Michele Di Mauro, MD, PhD, MSc, Cardio-Thoracic Surgery Unit, Heart and Vascular Centre, Maastricht University Medical Centre, P. Debyelaan 25, 6202 AZ, Maastricht, The Netherlands (E-mail: mdimauro1973@gmail. com).

JTCVS Techniques 2021;9:11-2

2666-2507

Copyright (C) 2021 The Author(s). Published by Elsevier Inc. on behalf of The American Association for Thoracic Surgery. This is an open access article under the CC BY-NC-ND license (http://creativecommons.org/licenses/by-nc-nd/4.0/).

https://doi.org/10.1016/j.xjtc.2021.06.024
}

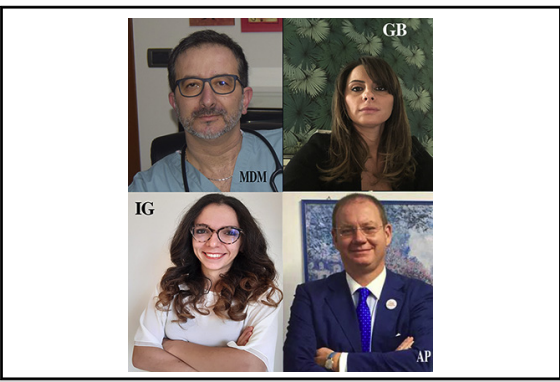

Michele Di Mauro, MD, PhD, MSc, Giorgia Bonalumi, MD, Ilaria Giambuzzi, MD, Alessandro Parolari, MD PhD

CENTRAL MESSAGE

The authors review the literature on type A dissection to address its influence on immediate outcomes and prognosis of false lumen and distal anastomotic new entry tear, and strategies to avoid them.

pressurization, leading to a negative aortic remodeling because, over time, it behaves as a primary entry tear. A DANE, therefore, carries a strong negative influence on survival and aortic events. Given this premise, White and colleagues ${ }^{4}$ provide an interesting summary on strategies to prevent DANE. The authors, in fact, strongly encourage total aortic in all patients, regardless the position of entry tear. The described solution is the employment of frozen elephant trunk, ${ }^{6,7}$ to move DANE downstream and, in case of failure of closure, an endovascular second-stage approach is still doable. Moreover, it has been shown that, despite being TAR technically more challenging and with higher risk of early mortality than nTAR, it is possible to equalize the gap between TAR and nTAR through institutional experience. ${ }^{8}$

What can we learn by reading the review by White and colleagues? ${ }^{4}$ First of all, a comprehensive and updated explanation on pathophysiological mechanisms of ATAAD, focusing on the effect of FL and DANE. Second of all, interesting considerations are added to the ongoing debate between choosing a less aggressive strategy versus a more aggressive strategy to treat ATAAD.

In a nutshell, if God never closes a door, without opening a window, aortic surgeons must shut all the entries. 


\section{References}

1. Bachet J, Goudot B, Dreyfus GD, Brodaty D, Dubois C, Delentdecker P, et al. Surgery for acute type A aortic dissection: the Hopital Foch experience (1977-1998). Ann Thorac Surg. 1999;67:2006-9.

2. Cabasa A, Pochettino A. Surgical management and outcomes of type A dissectionthe Mayo Clinic experience. Ann Cardiothorac Surg. 2016;5:296-309.

3. Heo W, Song SW, Kim TH, Lee JS, Yoo KJ, Cho BK, et al. Differential impact of intimal tear location on aortic dilation and reintervention in acute type I aortic dissection after total arch replacement. J Thorac Cardiovasc Surg. 2019;158: 327-38.e2.

4. White A, Bozso SJ, Ouzounian M, Chu WA, Moon MC. Acute type A aortic dissection and the consequences of a patent false lumen. J Thorac Cardiovasc Surg Tech. 2021;9:1-8.

5. Hagan PG, Nienaber CA, Isselbacher EM, Bruckman D, Karavite DJ, Russman PL, et al. The International Registry of Acute Aortic Dissection
(IRAD): new insights into an old disease. JAMA. 2000;283:897903.

6. Di Bartolomeo R, Di Marco L, Cefarelli M, Leone A, Pantaleo A, Di Eusanio M, et al. The Bologna experience with the Thoraflex ${ }^{\mathrm{TM}}$ hybrid frozen elephant trunk device. Future Cardiol. 2015;11:39-43.

7. Bertoglio L, Fittipaldi A, Giambuzzi I, Redaelli P, Verzini A, Cambiaghi T, et al Preliminary results of debranch-first technique in frozen elephant trunk procedures. Ann Thorac Surg. 2019;108:1345-53.

8. Ok YJ, Kang SR, Kim HJ, Kim JB, Choo SJ. Comparative outcomes of total arch versus hemiarch repair in acute DeBakey type I aortic dissection: the impact of 21 years of experience. Eur J Cardiothorac Surg. 2021; https://doi.org/10.1093/ejcts/ ezab189 [Epub ahead of print].

Key Words: aortic surgery, aortic dissection, entry tear, false lumen 